\title{
A produção acadêmica de mulheres professoras no campo do saber teológico: sujeição ou subjetivação ética?
}

\author{
Neiva Furlin ${ }^{1}$ \\ ORCID: 0000-0002-5103-2104
}

\section{Resumo}

A presença da docência feminina no ensino superior é uma conquista recente que foi se consolidando em meio a desafios, sobretudo, nos campos de saberes que se estruturaram como lugares exclusivamente masculinos, como é o caso da teologia. Nesse lugar, as mulheres precisaram produzir estratégias políticas, por meio de práticas situadas, para se afirmarem sujeitos de saber, superando barreiras de gênero da ordem simbólica masculina. Nesse sentido, este trabalho busca analisar as práticas acadêmicas das docentes, especificamente, as de orientação de trabalhos acadêmicos e as de publicação, evidenciando quais os sentidos produzidos para o processo de subjetivação ética ou de agenciamento de si. 0 estudo é baseado em narrativas de quatorze docentes, que atuavam em três instituições católicas, cujos conteúdos são analisados a partir dos pressupostos teóricos do feminismo e dos estudos de gênero, na perspectiva pós-estruturalista, nas definições que envolvem as relações de poder e seus efeitos, e os processos de resistência e de subjetivação ética. Resultados apontam que a ação acadêmica das docentes produz um efeito de contramemória a um modelo de feminino da ordem simbólica masculina. Para isso, elas interagem com as dinâmicas de poder existentes, neutralizando os feitos de um saber globalizante, como estratégia política de subjetivação ou agenciamento ético de si.

\section{Palavras-chave}

Docência feminina - Ensino superior - Práticas acadêmicas - Subjetivação ética.

1- Universidade do Oeste de Santa Catarina, Joaçaba - SC, Brasil. Contato: nfurlin@yahoo.com.br. 


\section{Academic production of women teachers in the field of theology: subjection or ethical subjectivation?}

\section{Abstract}

The presence of women professors in higher education has been recently achieve and has been consolidated amid challenges, especially in fields of knowledge that are dominated exclusively by men, as is the case of theology. Here, women need to produce political strategies by means of situated practices to assert themselves as knowledgeable, overcoming gender barriers of the male symbolic order. Thus, this study aims to analyze the academic practices of women professors, specifically in supervising academic studies and publications, showing the meanings produced for the process of ethical subjectivation or self-agency. The study is based on the narratives of 14 professors who worked in three Catholic institutions. The contents of the narratives are analyzed from a feminist theoretical framework and gender studies, with a post-structuralist perspective and definitions that involve relationships of power and its effects, and the processes of resistance and ethical subjectivation. Results indicate that the academic action of teachers produces a countermemory effect to a feminine model of the masculine symbolic order. For this, they interact with the existing dynamics of power, neutralizing the facts of a globalizing knowledge, as a political strategy of subjectivation or ethical self-agency.

\section{Keywords}

Female teaching - Higher education - Academic practices - Ethical subjectivation.

\section{Introdução}

A docência feminina no ensino superior tem sido uma conquista das últimas décadas em diferentes áreas acadêmicas e vem se afırmando em meio a desafios, sobretudo, nos campos de saberes que se estruturaram, ao longo de muitos séculos, como lugares exclusivamente masculinos. Aqui poderíamos citar as áreas da engenharia, da física, da matemática, da filosofia, da teologia, entre outras. Neste trabalho, interessanos discutir sobre algumas das práticas que envolvem o trabalho docente de mulheres que atuam no ensino superior na área da teologia católica e as dinâmicas de gênero que perpassam tais práticas.

As instituições católicas de ensino em teologia foram criadas em vista da formação para o ministério ordenado de homens. Historicamente, esse espaço foi marcado por formas de organização androcêntricas, que garantiram a supremacia do sujeito masculino nas instâncias hierárquicas do espaço eclesial e sua exclusividade na produção do discurso acadêmico teológico. As representações de gênero desse discurso, instituído no plano 
do sagrado e do simbólico, acabaram legitimando o saber teológico como um lugar não inteligível para as mulheres. No Brasil elas só tiveram acesso ao curso superior de teologia a partir da década de 1970, quando as mulheres foram cruzando as fronteiras demarcadas por gênero em diferentes áreas acadêmicas. Esse fenômeno ocorreu impulsionado pelas transformações socioculturais e pelas mobilizações feministas, as quais, indubitavelmente, também influenciaram o ambiente religioso e eclesial. Assim, a partir dos anos de 1980, as mulheres além de acessarem aos cursos de teologia, também foram se inserindo no campo do ensino e da produção acadêmica (FURLIN, 2016).

É importante mencionar que a graduação em teologia foi reconhecida pelo MEC, por meio do parecer do Conselho Nacional de Educação - CNE/CES n² 241/99, de 15 de março de $1999^{2}$ (BRASIL, 1999), o que trouxe maior visibilidade para essa área disciplinar no conjunto das ciências humanas, tornando-se um espaço de saber aberto para quem deseja acessar essa formação como um projeto profissional, para além da histórica formação para o serviço presbiteral (FURLIN, 2011).

Tal realidade tende a favorecer a inserção de mulheres no universo do saber teológico. No entanto, as instituições de ensino superior em teologia continuam sendo um reduto dos sujeitos masculinos, conforme apontamos em nosso estudo de tese, intitulada "Relações de gênero, subjetividades e docência feminina: um estudo a partir do universo do ensino superior em teologia católica"’. Nessa pesquisa mostramos que a graduação de teologia, entre os cursos que integravam a grande área das humanidades, era o que apresentava o maior índice de desigualdade em relação à participação da docência masculina e feminina. Isto é, uma diferença de 47,4 pontos percentuais ${ }^{4}$. Quando se considerou somente o universo das instituições de ensino em teologia católica, essa assimetria chegava a 71,2\% (FURLIN, $2014)^{5}$. Essa realidade, em parte, pode ser explicada pelas práticas discursivas dessas instituições que, ao longo dos séculos, legitimaram hierarquias sexistas no espaço eclesial e por ter vinculado o curso de teologia ao universo masculino, em vista do serviço ordenado.

Embora a presença da docência feminina nos cursos de teologia ainda seja bem reduzida, em termos quantitativos, ela ganha importância simbólica por revelar que as mulheres estão rompendo as fronteiras de gênero de um campo profissional demarcado culturalmente como masculino. Ou seja, trata-se de uma "subversão crítica”, no sentido de desestabilizar uma ordem social que parecia ser sagrada e intocável. Contudo, estar nesse lugar de saber exige das mulheres docentes um empreendimento de energias bem superior aos seus pares masculinos, para se legitimarem sujeitos de saber teológico. "A meta é pôr em prática, aqui e agora, um modo de representação onde o fato de ser mulher tenha a conotação de uma força política positiva e auto-afirmante.” (BRAIDOTTI, 2004, p. 45).

Portanto, o presente trabalho prioriza analisar as práticas de produção acadêmica das docentes no que diz respeito às orientações de monografias, dissertações e teses, e as

\footnotetext{
2- Até então, esses cursos eram considerados "cursos livres" em teologia.

3- Tese defendida em 2014, pelo Programa de Pós-graduação em Sociologia da UFPR.

4- Dados do Censo sobre o Ensino superior de 2005, coletados em 93 instituições (presbiterianas, luteranas, metodistas e católicas). Dessas instituições, aproximadamente, a metade era de orientação católica.

5- No que se refere à presença feminina em funções de liderança, como em coordenação de curso, a pesquisa tem mostrado uma expressão minoritária, mas que exerce poder simbólico no sentido de que elas também são capacitadas para tais funções. Maiores detalhes sobre isso, consultar Furlin (2014).
} 
publicações, evidenciando as dinâmicas de gênero e os sentidos produzidos no processo de subjetivação ética ou de agenciamento de si.

Trata-se do recorte de um estudo de tese, em que se buscou compreender como as mulheres se construíam sujeitos de saber e de poder em um lugar historicamente masculino, atravessado por dinâmicas de gênero que deram supremacia ao poder, às práticas e aos discursos teológicos, produzidos desde a ótica da subjetividade masculina. Sendo os homens os sujeitos históricos da produção do saber teológico, da mesma forma que em outras áreas do conhecimento, esse saber reproduziu valores e interesses da cultura patriarcal. Segundo Schienbinger (2001), a visão masculina estruturou o conhecimento, desvalorizando e negligenciando a participação histórica das mulheres nos processos socioculturais, já que as dinâmicas de gênero estabeleceram prioridades científicas, estruturando silenciosamente teorias e práticas sociais. Tanto os discursos filosóficos e científicos da modernidade quanto o da teologia tradicional legitimaram a universalização e a institucionalização de estruturas sociais hierárquicas e androcêntricas.

$\mathrm{Na}$ teologia esses discursos produziram a diferença como pejorativa, apoiando-se no pensamento grego, especificamente nos dualismos da filosofia de Aristóteles e nas tradições do judaísmo, cujas ideias e representações influenciaram a filosofia e a teologia moral de Agostinho e de Tomás de Aquino. Tais obras continuam sendo referências nos programas dos cursos de teologia católica. Trata-se de um discurso que foi performatizando e naturalizando práticas sociais discriminatórias que legitimavam a exclusão das mulheres em espaços de liderança eclesial e em práticas que envolviam a racionalidade.

Assim, analisar as práticas acadêmicas de mulheres docentes inseridas no campo do saber teológico, em seu processo de devir sujeitos femininos de saber, pode nos remeter a outras áreas de saber, que ainda são majoritariamente masculinas. Contudo, poderia se afirmar que no campo da teologia o processo de desconstrução das hierarquias de gênero legitimadas ao longo de muitos séculos, por representações simbólicas advindas do universo do sagrado, pode ter desafios mais profundos que outras áreas, considerando que a teologia ${ }^{6}$ se configurou como esforço reflexivo (logos) sobre Deus (theos) e a vivência que se tem de Deus, realizada a partir da riqueza da experiência da crença. Na compreensão atual, ela é considerada uma ciência humana de perspectiva hermenêutica, cujo objetivo é desvelar o sentido último e transcendente da vida humana (LIBANIO; MURAD, 2011).

Vale recordar que, segundo os estudos epistemológicos das últimas décadas, como os de Schienbinger (2001), Felski (1995) e Harding (1996), nenhum saber é totalmente neutro, porque a visão de mundo, a posição social e os interesses dos sujeitos demarcam os saberes produzidos. Nesse sentido, na teologia as representações masculinas da divindade legitimavam as estruturas patriarcais, não somente no universo eclesial, mas na própria cultura. E isso corrobora a ideia de que os discursos simbólicos teológicos não são uma construção neutra, e sendo produzidos por uma elite masculina celibatária, nos termos de Gebara (2008), ou por uma intelligentsia masculina, esses sujeitos falam, escrevem e pensam a partir de determinado "lugar social", expondo, assim, os seus engajamentos, os seus valores e as suas crenças culturais (MANNHEIM, 1976). Consequentemente, as

6- Acredita-se que uma pessoa que possui algum contato com a teoria feminista ou com os estudos de gênero consegue perceber e problematizar melhor as dinâmicas de gênero que circulam no cotidiano das práticas sociais. 
representações e os significados de gênero também orientaram a construção do simbólico, as interpretações dos textos bíblicos, a produção e a legitimidade dos discursos. E, nesse caso, discursos teológicos que legitimaram as desigualdades de gênero, por meio da construção de representações do feminino como inferior e desqualificado para funções intelectuais.

Desse modo, é significativo analisar como as práticas situadas das mulheres docentes podem contribuir para a subjetivação ética ou o agenciamento de si, no campo do saber teológico, majoritariamente masculino.

\section{Pressupostos teórico-metodológicos}

Este estudo se baseia em narrativas de quatorze docentes ${ }^{7}$ que atuavam no ensino superior em três instituições católicas. Entre os critérios para a seleção das docentes se estabeleceu que elas tivessem formação em teologia católica; que ministrassem aulas no curso de graduação em teologia; que tivessem produção na perspectiva feminista ou de gênero, ou que tivessem tido algum contato com as teorias de gênero e do feminismo durante o processo de sua formação acadêmica ${ }^{8}$; que fossem professoras de instituições com o curso de teologia, autorizado ou reconhecido pelo MEC, localizadas geograficamente nas regiões Sul e Sudeste do Brasil. A escolha por interlocutoras de instituições dessas duas regiões se deve, primeiramente, porque nelas se encontrava a presença mais significativa de docentes que produziram e publicaram artigos e livros utilizando as abordagens de gênero e do feminismo. Em segundo lugar, porque nessas regiões se concentrava o maior número de instituições que ofereciam o curso de teologia e onde estavam situadas as instituições com maior reconhecimento, em termos acadêmicos ${ }^{9}$.

As entrevistas em profundidade possibilitaram que as docentes narrassem suas trajetórias de inserção no campo acadêmico teológico, suas ações, relacionamento com seus pares, os processos de resistência às convenções culturais do campo e as experiências vividas no exercício das atividades acadêmicas ${ }^{10}$.

Para este artigo, tomamos exclusivamente as narrativas sobre as práticas de orientação de trabalhos acadêmicos e publicações, a fim de evidenciar como essas docentes produzem suas possibilidades de agenciamento ético, no sentido de uma afırmação positiva do feminino, que opera como contramemória ao feminino produzido pelos discursos da teologia androcêntrica.

É um estudo qualitativo, pautado na compreensão hermenêutica, segundo os pressupostos de Maria Cecília Minayo (2003) que, além de permitir a interpretação e de estabelecer relações em diferentes direções, possibilita a intersubjetividade entre o sujeito pesquisador e o sujeito pesquisado, em um processo de compreensão e autocompreensão.

\footnotetext{
7- Adotamos um nome fictício para as interlocutoras, obedecendo aos procedimentos éticos estabelecidos para a pesquisa científica.

8- Acredita-se que uma pessoa que possui algum contato com a teoria feminista ou com os estudos de gênero consegue perceber e problematizar melhor as dinâmicas de gênero que circulam no cotidiano das práticas sociais.

9- Dados levantados em pesquisa de campo em 2008 e 2009.

10- As entrevistas foram realizadas no ano de 2009.
} 
Em outras palavras, coloca o pesquisador e pesquisado em relação analítico-interpretativa. Para Minayo (2003, p. 92):

Compreender implica a possibilidade de interpretar, de estabelecer relações e extrair conclusões em toda a direção. Mas compreender acaba sempre sendo compreender-se. A estrutura geral essa forma de abordagem atinge sua concreção na compreensão histórica na medida em que aí se tornam operantes as vinculações concretas de costumes e tradições e as correspondentes possibilidades de seu futuro.

Essa proposta metodológica desloca o pesquisador da posição de protagonista da verdade científica, para um olhar que considera a posição relacional entre os sujeitos. Uma relação que é muito mais que a simples aproximação com as interlocutoras, porque se trata de uma postura em que a pesquisadora se deixa tocar por suas narrativas, problematizando-as por meio de um olhar crítico e teórico.

Somado a isso, adotamos a perspectiva genealógica de Teresa de Lauretis (2000), que considera a singularidade das práticas e experiências situadas como forma de compreender as condições nas quais os processos de subjetivação feminina ocorrem no universo da teologia. Trata-se de um constituir-se no "aqui e agora”, em meio às dinâmicas de gênero do sistema simbólico masculino, como é o caso no universo do saber teológico. Não é uma história do passado, mas do presente. No sentido de Braidotti (2004), as genealogias dos sujeitos - mulheres - produzem-se como contramemória às dinâmicas de poder e de gênero do sistema simbólico masculino.

Analisamos os conteúdos das narrativas das docentes à luz dos pressupostos teóricos do feminismo e dos estudos de gênero, na perspectiva pós-estruturalista, nas definições que envolvem as relações de poder e seus efeitos, e os processos de resistência e de subjetivação ética. Destacamos, aqui, os principais conceitos que atravessam a compreensão hermenêutica deste estudo: a) Gênero desde a perspectiva de Joan Scott (1990) e Tereza de Lauretis (1994); b) Poder como uma relação produtiva, conforme as noções de Michel de Foucault (1999) e Judith Butler (2007); c) Subjetividade ética na compreensão de Foucault $(2004,2007)$, pensada como a constituição de si por meio de atos de liberdade, resistência e de reflexividade diante das convenções normativas que limitam as condições do sujeito; d) Diferença sexual segundo a compreensão de Braidotti (2004), como um processo de positivação da diferença ou da produção de um feminino alternativo ao modelo do sistema simbólico masculino. Para isso, Braidotti focaliza a resistência na prática política feminista e na localização do corpo encarnado, para produzir efeitos de contramemória. É partindo da perspectiva da prática localizada que ela propõe uma versão não essencializada da diferença sexual, em que o eu encarnado se define com a intersecção de muitos campos de forças sociais, como raça, idade, cultura. Se o sistema simbólico masculino colonizava o imaginário das mulheres, para Braidotti, "o projeto do feminismo deve tanto resistir como abrir espaços alternativos para as mulheres redefinirem coletivamente suas experiências singulares como o "outro de si mesmas'". (BRAID0TTI, 1999, p. 16); e) Agência ética compreendida uma forma de ação política, conforme Butler (2003, 2009a, 2009b), que, em certa medida, corresponde ao sujeito ético 
da compreensão de Foucault. Para Butler (2009b), agência nunca está de todo determinada e nem é totalmente livre. Sua luta ou seu dilema principal é o fato de ser produto de um mundo, mesmo quando, de alguma forma, se produz por si mesmo.

Em Butler, o poder da agência é fundamentalmente resistência. Surge quando ocorre uma descontinuidade entre o poder que constitui o sujeito e o poder que o próprio sujeito assume. Em palavras de Butler (2010, p. 9): "a agência excede ao poder que lhe faz possível." É esse excesso que oferece a possibilidade de ressignificação que surge do desejo do sujeito, e o desejo "tem por objetivo a dissolução do sujeito", que, nesse caso, trata-se do sujeito conformado com as convenções sociais. Em Braidotti (2004), a agência também se conecta com o processo de resistência ao sistema simbólico masculino que produziu subjetividades femininas pejorativas e estáveis, de maneira que o potencial subversivo da agência se encontra na relativa não pertença a esse sistema, o que lhes permite negociar ou produzir formas alternativas de sujeito.

Esses pressupostos teóricos são fundamentais para compreender os processos de resistência ao sistema simbólico de gênero da ordem social masculina, que construiu o feminino como inferior e despossuído de razão, bem como as estratégias políticas que as docentes criam para se produzirem sujeitos femininos de saber, no cotidiano da profissão da docência, em um lugar marcadamente masculino.

\section{A prática docente de orientação: dinâmicas de poder e de gênero}

Sobre a orientação de trabalhos de conclusão da graduação e da pós-graduação ${ }^{11}$, as docentes afirmam que são muito procuradas pelos/as discentes e que chegam a orientar mais trabalhos acadêmicos que seus pares masculinos. Evidentemente que, em geral, elas não são procuradas por serem mulheres, mas porque são boas professoras capazes de despertar interesse dos alunos/as para os temas que elas aprofundaram ou porque eles/ as têm interesse em estudar conteúdo da linha de pesquisa em que elas estão vinculadas, como se pode ler no fragmento que segue:

Os alunos e alunas me procuram muito para a orientação de trabalho acadêmico. Oriento na área de moral, também na sistemática, porque eu trabalho com disciplinas de antropologia teológica, escatologia e tratado da graça. Então os alunos me procuram também nessas áreas. Olha que eu tenho orientado, quase mais que os homens, se não mais. (Priscila, 60 anos).

0 argumento de que são muito procuradas aparece no relato das docentes entrevistadas de três instituições. "Os alunos pedem muito. Eu estou com o maior grupo de orientação de trabalhos interdisciplinares. As orientações vão desde as linhas bíblicas até da teologia feminista." (Maria, 61 anos). Considerando as dinâmicas de gênero, que circulam neste espaço acadêmico, a procura maciça de alunos, sejam quais forem os seus

11- Quando nos referimos aos dados empíricos sobre a orientação de trabalhos na pós-graduação, estes se referem somente a cinco docentes, em cuja instituição, na época da pesquisa, existia o mestrado e doutorado. 
interesses, acaba conferindo afırmação profissional, legitimidade e poder para as mulheres. Sabe-se que o produtivíssimo acadêmico é hoje uma imposição para os/as docentes diante das exigências por resultados que medem os índices alcançados pelas universidades. Contudo, para essas mulheres, isso se torna um dispositivo de poder, de reconhecimento e de afırmação positiva, em um espaço em que se reproduziram representações de gênero os quais constituiam o feminino como inferior e incapaz de ações que envolviam o pensamento intelectual. A reiteração, aqui, torna-se uma estratégia política e performativa que produz um deslocamento subjetivo do feminino construído como desqualificado para atividades intelectuais para um feminino que se produz sujeito de saber, por meio das práticas situadas. No sentido de Butler (2010), trata-se de um agenciamento ético de si que se produz pela descontinuidade entre o poder que as constituíram como inferiores e o poder que elas assumem nesse lugar de saber, como seres de razão intelectual.

Por outro lado, as narrativas evidenciam que, em algumas instituições, o fato de as docentes serem as mais buscadas para orientações tem sido motivo de disputa de poder, por parte daqueles que veem "o seu lugar" sendo "ocupado" por outro sujeito, que é mulher e que, até então, não era considerada inteligível nessa configuração social. Das docentes que tinham um contrato de 40 horas semanais, apenas duas disseram ter poucas orientações. Uma delas, embora veterana na teologia, tinha sido contratada por tempo integral em um período recente e somente agora poderia assumir mais orientações e, a outra, tinha apenas um ano de inserção na docência. Sabe-se que orientar trabalhos é uma prática acadêmica, inerente ao exercício da docência, entretanto, para elas, o "orientar mais" parece funcionar como uma estratégia de produção de sua legitimidade acadêmica, como um sujeito profissional que, politicamente, precisa produzir outra imagem da "mulher", que ganha expressão por meio de sua ação incorporada, em um contexto de supremacia masculina No sentido de Lauretis (1994), essa prática contextualizada poderia ser compreendida como uma tecnologia de gênero que ressignifica o feminino. Em Braidotti (2004), isso se interpreta como uma forma de fazer valer a positividade da diferença sexual e de tirar as mulheres do armário da alteridade desvalorizada, no qual elas foram confinadas historicamente.

A tabela, apresentada abaixo, ilustra a participação das docentes na orientação de trabalhos de conclusão de curso, neste caso, especificamente no programa da pósgraduação em teologia da PUC-RIO. Vale ressaltar que a primeira turma de mestrado dessa universidade iniciou no primeiro semestre de 1972 e, no mesmo ano, seu Conselho de Ensino e Pesquisa aprovou o curso de doutorado em teologia. No entanto, durante esta década se tem o registro de quinze defesas de dissertações, todas sob orientação de professores homens, porque as mulheres, praticamente, não tinham representação na participação docente. Elas começam a orientar na década de 1980, quando muitas estavam fazendo seus doutorados, conforme os dados levantados nas entrevistas.

Ao estabelecer um olhar sobre a participação das docentes nos trabalhos de conclusão do curso é necessário considerar que até a década de 1980 o número de mulheres docentes dessa universidade era em média de três para dezoito homens ${ }^{12}$. Somente no final da década de 1980, quando o grupo da segunda geração de mulheres foi concluindo o doutorado

12- Informações coletadas nos catálogos anuais do curso de teologia da PUC-RIO. 
e se inserindo na docência é que esse número aumentou de seis a sete mulheres para dezessete a dezenove homens, cuja média se manteve desde o início dos anos noventa até o momento do nosso estudo. Considerando a presença reduzida de mulheres na docência em teologia, a sua participação na orientação de trabalhos acadêmicos é relevante, pois de 344 dissertações e teses defendidas até setembro de 2013, 104 foram orientadas por mulheres e 240 por homens, o que corresponde, respectivamente, a 30,2\% para 69,8\%. Esses números equivalem, de forma aproximada, à porcentagem da presença das mulheres nessa instituição. E, levando em conta os números da tabela a seguir, podemos evidenciar que as docentes mulheres, embora tendo uma presença reduzida, aparecem com uma participação igual ou superior aos homens, quando se trata de orientações de teses e dissertações.

Tabela 1 - Número de orientações de dissertações e teses do programa de pós-graduação em teologia, por período, segundo o sexo do docente

\begin{tabular}{|c|c|c|c|c|c|}
\hline \multirow{2}{*}{$\begin{array}{l}\text { TIPO DE TRABALHO } \\
\text { Ano / Orientador(a) }\end{array}$} & \multicolumn{2}{|c|}{ DISSERTAÇÕES } & \multicolumn{2}{|c|}{ TESES } & \multirow[b]{2}{*}{ TOTAL de orientações } \\
\hline & Mulheres & Homens & Mulheres & Homens & \\
\hline $1971-1980$ & 00 & 15 & 0 & 00 & 15 \\
\hline $1981-1990$ & 01 & 40 & 02 & 04 & 47 \\
\hline $1991-2000$ & 30 & 50 & 07 & 25 & 112 \\
\hline $2001-2010$ & 34 & 50 & 18 & 34 & 136 \\
\hline $2011-2013$ & 10 & 18 & 02 & 04 & 34 \\
\hline TOTAL & 75 & 173 & 29 & 67 & 344 \\
\hline$\%$ total de cada categoria & $30,2 \%$ & $69,8 \%$ & $30,2 \%$ & $69,8 \%$ & \\
\hline
\end{tabular}

Fonte: FURLIN, Neiva. Pesquisa biblioteca online - PUC-RIO, out. 2013.

A tabela 1 apresenta, em separado, números e porcentagens referentes a cada categoria, ou seja, teses e dissertações. Se olharmos para a porcentagem das orientações feitas por mulheres, verifica-se que elas têm orientado, de maneira equilibrada, o mesmo número de teses e dissertações (30,2\%), assim como os homens $(69,8 \%)$. Essa porcentagem, sem dúvida, é significativa considerando que elas são uma presença minoritária na docência e que iniciaram o trabalho de orientação uma década mais tarde que os homens. É, praticamente, a partir da década de 1990 que elas apresentam uma atuação mais significativa na atividade de orientação de trabalhos acadêmicos na pós-graduação, cuja contribuição se torna importante, sobretudo, quando essas orientações tendem a ser dentro das áreas mais significativas da teologia, como da sistemática, bíblica e moral.

Se direcionarmos, por exemplo, o olhar para a década de 2001-2010, nota-se uma congruência com as narrativas das docentes, as quais diziam ter mais orientações que seus colegas homens. Isso porque, observando o número reduzido de mulheres professoras em relação aos homens que atuavam na PUC-RIO, o fato de elas terem orientado trinta e quatro dissertações enquanto os homens orientaram cinquenta e de terem orientado dezoito teses enquanto eles orientaram trinta e quatro, evidencia que, embora esse trabalho lhes confira certo reconhecimento e legitimidade acadêmica, na posição de sujeitos de saber, elas 
também aparecem sobrecarregadas, porque orientam mais da metade dos trabalhos. Se o nível de produtividade é um dispositivo de poder que dá legitimidade às mulheres, dentro dos cursos de teologia, de maneira contraditória, tende a ocultar dinâmicas desiguais de gênero, sobretudo porque, além de um trabalho supra-humano na academia, muitas precisam dar conta de outras responsabilidades, que vêm do cotidiano de suas vidas, das outras posições de sujeito ou de identidade em que estão implicadas, como as de: mãe, esposa, religiosa, ou agente de pastoral ${ }^{13}$.

Nota-se a existência de certa cumplicidade com as hierarquias e relações desiguais de gênero, constituídas por representações simbólicas de gênero impregnadas nas práticas institucionais, conforme acentua Scott (1999), em seus estudos. Nessa contradição, do estar dentro e fora da ordem simbólica patriarcal, no sentido de Lauretis (1994), as docentes se submetem à lógica do intenso trabalho como uma estratégia de sua afirmação no processo do devir sujeito feminino e na necessidade de marcar esse lugar de saber com uma posição positiva. Em outras palavras, o desejo de vir a ser sujeito feminino de saber reconhecido no campo teológico se encaixa com o desejo de cumprir as normas acadêmicas, cuja relativa submissão de maneira paradoxal, desconstrói sentidos de gênero da ordem patriarcal.

Contudo, vale ressaltar que essa sujeição pode trazer um efeito contrário, que é a reprodução de relações desiguais de gênero, ou seja, naturaliza-se a ideia de que as mulheres precisam fazer tudo mais e melhor, para ter o mesmo direito de reconhecimento acadêmico, enquanto sujeito de saber. A realidade de intensificação do trabalho das docentes, como estratégia de reconhecimento, tem se verificado em estudos sobre outras áreas do conhecimento, também consideradas masculinas, ao longo da história, como é o caso das engenharias e outras ciências exatas ${ }^{14}$.

Desse modo, se em algumas situações a maior procura de alunos/as pelas professoras mulheres, para orientações de teses e dissertações pode ter sido motivo de disputa de poder por status e visibilidade acadêmica ${ }^{15}$, a sobrecarga de trabalhos monográficos pode estar relacionada à exigência de uma "eficiência profissional" que acaba sendo demandada mais das mulheres, sobretudo, quando esse espaço tem sido historicamente o lugar do sujeito masculino, em que o gênero demarca hierarquias de poder (SCOTT, 1999). Por outro lado, sabe-se que a orientação de monografias requer um acompanhamento maior aos estudantes, por ser a fase inicial da construção de um pesquisador. Assim, por essa razão, tal atividade pode ser mais direcionada às mulheres que aos homens, dada as concepções tradicionais de gênero e, talvez, por esse motivo, os professores homens prefiram atividades que lhes deem maior status acadêmico ${ }^{16}$. A sobrecarga de orientações,

13- Tal questão foi abordada nas narrativas, contudo, como essas mulheres conciliam o seu cotidiano de vida com a profissão docente é uma janela que se abre para um possível estudo, que parece não caber aqui, devido à complexidade que envolve essa problemática.

14- 0 estudo de Maria Rosa Lombardi (2005) tem mostrado os desafios que as mulheres enfrentam nas engenharias, mas, ao mesmo tempo, a inserção de mulheres neste universo acadêmico também significa o rompimento de valores que tendem a discriminar as mulheres em carreiras predominantemente masculinas.

15- Diferentes professoras disseram perceber relações de ciúmes e competição por parte de seus pares, quando elas eram muito procuradas pelos estudantes, sobretudo quando estes eram considerados "brilhantes".

16 - Como os dados da tabela foram coletados depois da realização das entrevistas, não foi possível verificar concretamente os motivos dessa sobrecarga das mulheres nos processos de orientações de trabalho, que aparece nesta última década, uma vez que a preocupação primeira era saber se essas mulheres tinham ou não uma participação significativa na orientação de trabalhos de conclusão de curso. 
que se observa na tabela, só foi apontada por apenas uma das interlocutoras, conforme se observa na narrativa que segue:

Pode-se se pegar várias orientações por ano. Os alunos que se identificam com a gente acabam procurando orientação, mais do que com outros. Mas tem também o lado institucional, pois o professor pode ter umas cinco ou seis orientações de monografias e mais as aulas. Tem professor que pode orientar mais, mas não pega porque dá trabalho e acaba pegando um ou dois alunos e, assim muitos ficam sobrando, ficam sem orientador. Então há toda uma estratégia que se tem que fazer. Antigamente eu até pegava mais para ajudá-los. Atualmente eu pego só o que devo pegar. Eu não fico mais quebrando o galho dos outros. Eu cheguei num certo patamar, que se eu perceber que a coisa está sendo uma forma de explorar a mulher na teologia, eu não vou. Atualmente, eu não tenho medo, eu ganhei o meu espaço, eu digo não vou fazer isso, eu não aceito. Eu falo isso claramente nas reuniões. Eu estou lá há mais tempo que eles. Eu tenho um espaço garantido, não tenho medo de ser demitida. Na orientação de monografias eu não aceito quebrar galho de padre. Eles não podem, eu também não posso. (Madalena, 55 anos).

Madalena diz ter aceitado mais alunos do que deveria, no sentido moral de uma boa ação diante da omissão de seus colegas. Entretanto, mais do que uma boa ação, o orientar mais alunos no início da carreira de docente, em um lugar que havia sido interditado para as mulheres, é, certamente, uma estratégia política que dá visibilidade à ação feminina e certa legitimidade ao processo do "tornar-se professora", sujeito feminino de saber teológico. Outro aspecto que a narrativa de Madalena apresenta é a possibilidade de maior autonomia que lhes advém do acúmulo do capital simbólico ${ }^{17}$ - anos de trabalho, reconhecimento, experiência -, o que lhes permite maior liberdade para orientar suas escolhas e assumir a posição de um sujeito capaz de refletir, jogar o mesmo jogo de seus pares e de resistir diante de dinâmicas desiguais de gênero. Trata-se de um produzirse que ocorre entre a contradição do assujeitamento às convenções sociais do universo acadêmico e posições perpassadas por atos de liberdade, de reflexividade e de resistência que, na concepção de Foucault (2007), nunca ocorrem de forma autônoma, mas vinculadas às relações de poder. Poder-se-ia ler-se essa atitude em termos de agência ética, no sentido de Butler (2009a), porque a ação de Madalena ocorre no contexto das relações sociais do universo teológico. É uma ação autoafirmativa e reflexiva em que, movida pelo desejo de justiça, ela toma consciência das dinâmicas institucionais de poder, das quais tinha sido cúmplice por causa dos ganhos que poderia ter, mas que agora pode assumir uma postura política que se opõe a um imaginário de mulher submissa, cumpridora de tarefas, para uma mulher autônoma, que sabe ter direitos iguais, adquiridos pelo processo de formação profissional, sem a necessidade de continuar conquistando esse direito por meio da sobrecarga de trabalho. 0 devir sujeito é, assim, sempre um processo de mudança, uma passagem de um estado para o outro, cuja possibilidade ocorre por meio da reflexividade e da consciência crítica, que são acionadas na interação com os dispositivos de poder que se exercem dentro de um contexto específico.

17 - Em Bourdieu (2003), o capital simbólico, como todas as formas de capital, precisa ser reconhecido e percebido pelos agentes de determinado campo e de campos afins, e a percepção e o reconhecimento comum atribuem valoração e funcionam como critério de distribuição dos agentes no interior do campo social. 
Nesse sentido, parece relevante a concepção de Butler (2009b), de que o poder da agência emerge da resistência e surge quando acontece uma descontinuidade entre o poder que constitui o sujeito (mulher inferior) e o poder que o próprio sujeito assume (mulher autônoma, com direitos iguais, possuidora de potencial intelectual). Em Braidotti (2004), isso pode ser lido no sentido de contramemória ou contragenealogia, em que se desconstrói o sistema simbólico masculino por meio da produção de um simbólico alternativo, que é de autoafirmação e a positivação do signo "mulher". Essa positivação não parece se constituir em uma nova essencialização, porque parte do presente, da ação de mulheres incorporadas em um contexto distinto. Na perspectiva de Lauretis (2000), trata-se de uma genealogia da história do presente, do "aqui e agora", em que um sujeito se produz por meio de práticas situadas, em meio às contradições das dinâmicas de gênero de uma ordem social masculina. Ou seja, é um sujeito mulher não mais apenas produto simbólico e abstrato dos interesses masculinos, mas um sujeito real, que é capaz de ação, de escolhas e de produzir-se, mesmo que essas escolhas lhe exigem ter que submeter-se a lógicas desiguais em termos de montante de trabalho, já que o fim é algo maior, ou seja, a desconstrução de uma imagem negativa do feminino e sua própria legitimação como um sujeito de razão.

\section{A publicação das docentes: abordagens e sentidos}

A produção do conhecimento e a publicação são exigências da atividade docente, sobretudo de quem está vinculado em programas de pós-graduação. Contudo, essa atividade, em contexto de política econômica neoliberal, tem sido submetida a metas produtivistas que serve para classificar as universidades na lista dos rankings, segundo certos critérios padronizados de qualidade.

Considerando que no universo da teologia a capacidade intelectual tem sido considerada, historicamente, um atributo masculino, a produção e a publicação se constituem para as mulheres um dispositivo de poder, no sentido foucaultiano, que lhes permite desconstruir concepções hierárquicas de gênero que ao longo de muitos anos inferiorizaram as mulheres. Isto é, produzir e publicar conhecimento, neste lugar de saber, torna-se uma estratégia política de subjetivação ética no sentido de Foucault ou de agência ética na concepção de Butler (2009a, 2009b), porque permite o deslocamento subjetivo em termos de significado de gênero. Isto é, por meio de práticas concretas e situadas se faz a passagem de um feminino que tinha sido constituído, pelo poder dos discursos masculinos, como incapaz de atividade intelectual, para um feminino que também é dotado de razão. Assim, exceder ao poder que constitui um sujeito, na concepção de Judith Butler, é uma forma de agência ética, pois nesse processo ocorre a produção de um novo significado ou de uma afirmação positiva para a identidade feminina.

Praticamente todas as docentes mencionaram ter escrito e publicado livros e artigos. Entretanto, o nível de produção de publicação está vinculado ao tempo de docência, a forma de contrato institucional ${ }^{18}$, ao seu reconhecimento no universo teológico e, sobretudo, com a sua inserção ou não em uma instituição de maior prestígio acadêmico, que tem certa referência em pesquisa científica. Isso faz com que o número quantitativo de publicações

18- Quando a docente possui um contrato de 40 horas, a produção tende a ser maior, uma vez que isso lhe permite mais tempo dedicado à pesquisa. 
seja diversificado, como se observa no relato de algumas docentes: “[...] Artigos, tenho mais de 100. Tenho uns 20 livros publicados. Nos últimos anos, coincidentemente, saíram vários livros, inclusive alguns em mais de uma língua: em português, espanhol e italiano. Tenho também muitos capítulos de livros" (Débora, 60 anos). Essa docente é a que mais tem publicações e orientações, das que foram entrevistadas, seguidas por outras, como é o caso da professora Rute (67 anos): “[...] eu só escrevi um livro, organizei três livros e escrevi um em conjunto com outro teólogo. Tenho ainda mais de 70 artigos.”

As que haviam sido contratadas recentemente no ensino da teologia com 40 horas e as que trabalhavam 20 horas semanais, conciliando a docência com outros trabalhos profissionais, disseram ter pouca publicação, em torno de um livro e meia dúzia de artigos. Outras mencionaram ter somente dois a três artigos e um ou dois capítulos de livro ${ }^{19}$. As professoras também alegaram que os colegas do sexo masculino geralmente estavam mais liberados para a vida acadêmica e, por isso, tinham mais tempo e disponibilidade para a pesquisa. Isso porque, nas instituições maiores, quase todos são contratados com tempo integral e as mulheres, dependendo da instituição, muitas vezes, são contratadas como "horistas" 20 ou por 20 horas. Evidentemente, esse tipo de contrato, como também ocorre em outros contextos acadêmicos, não potencializa um processo sistemático de pesquisa teológica, por mais que haja esforço. E tratando-se de um contrato reduzido, em geral, essas mulheres acabam se envolvendo com outros trabalhos fora da academia ${ }^{21}$.

Quando se analisa a produção acadêmica das mulheres, também é possível constatar a existência de dinâmicas que constroem desigualdades de gênero nas relações que se estabelecem no interior do campo de saber teológico. Segundo Schienbinger (2001), um dos grandes fatores da menor produtividade das mulheres nas ciências tem a ver com a questão da maternidade que as envolve mais que aos homens e, também, porque elas ocupam posições mais baixas em universidades importantes e estão, geralmente, em maior número nas universidades de menor prestígio e, por conta disso, movimentam menos recursos. Isso nos remete também para o universo da teologia, uma vez que as mulheres que produzem menos estão inseridas em pequenas faculdades, com contrato mais reduzido e sem recursos para a pesquisa.

Se, por um lado, ainda se constatam processos de discriminação e de desigualdade, em relação à produtividade acadêmica, por outro, não se pode negar que algumas dessas docentes têm marcado esse lugar de saber por meio da produção de uma teologia alternativa, partindo de referenciais teóricos dos estudos feministas e de gênero ${ }^{22}$, mesmo que essa produção seja minimamente lida ou indicada como referência bibliográfica pelos seus colegas do sexo masculino. A teologia feminista ou teologia pautada pelas abordagens dos estudos de gênero, que muitas delas afirmam ter produzido, mais do que se constituir em uma contribuição para o universo do saber teológico e para processos de mudança nas estruturas acadêmicas, tem sido uma ferramenta que possibilitou a

\footnotetext{
19 - Na categoria das que menos publicaram se encontravam as que estavam cursando o doutorado.

20- Contrato por número de horas semanais.

21- Chamou-nos atenção a sobrecarga de responsabilidades por parte de uma professora que, além do contrato de 20 horas-aula, coordena uma das outras modalidades de formação teológica oferecida pela instituição e, ainda, tem a coordenação de um projeto social e mais as atividades próprias da instituição religiosa a que pertence.
}

22- Situa-se no campo da produção de novos significados que, consequentemente, possibilita a reinvenção da subjetividade feminina, como é 0 caso da teologia feminista. 
produção de novos significados de gênero e, consequentemente, uma nova reinvenção de si. Uma forma de resistência ao poder da ordem simbólica masculina que, historicamente, invisibilizou as mulheres ou as produziu como seres inferiores e desqualificados para as atividades intelectuais.

Considera-se, assim, que é partindo dessa posição política que as docentes produzem o que nomeiam teologia feminista e afirmam que essa reflexão é uma nova proposta de produção de conhecimento, porque se contrapõe ao saber racional, universal e parcial, produzido do ponto da subjetividade masculina. Nesse sentido, a narrativa de Miriam (66 anos) ilustra essa concepção, que é compartilhada entre as docentes entrevistadas.

\begin{abstract}
A teologia feminista se constrói a partir de outra metodologia. Com certeza ela pode ser considerada uma nova proposta epistemológica dentro do campo da teologia, porque ela diz respeito ao conhecimento. Então, você vai caminhando por trilhas novas na produção desse conhecimento, onde se critica o conhecimento que foi feito e a forma como esse conhecimento foi feito até aqui. Por exemplo, a teologia feminista propõe outros aspectos, não entra só a racionalidade fria, entram dados empíricos, dados mais emocionas aonde a pessoa vem inteira e não coloca só a razão quando escreve e, isso enriquece epistemologicamente. Eu acho que é um ganho, é um ganho epistemológico. Você pode admitir que outras leituras podem ser feitas a partir de outro ponto de vista e a partir de um sentir diferente, que vem da experiência das mulheres.
\end{abstract}

Nesse e noutros fragmentos das narrativas, as docentes enfatizam assumir uma metodologia do ponto de vista das experiências das mulheres, que é tomada como base para a crítica da teologia tradicional, fundada na razão e na abstração. Elas afirmam que a metodologia que assumem incorpora o "cotidiano da vida, a emoção, a pessoa inteira (corporeidade)", de modo que o incorporar a pessoa inteira tem a ver com o todo da vida e do cotidiano de um sujeito que tem uma corporalidade de "mulher" e, isso, de acordo com os estudos mais contemporâneos do feminismo, é um primeiro lugar de resistência política, dada a construção negativa em relação ao feminino.

Segundo Gayatri Spivak (1985), o corpo encarnado não é uma essência nem um destino biológico, antes é a própria localização primária no mundo, a própria situação na realidade. A ênfase colocada na encarnação ou incorporação, ou seja, na natureza situada da subjetividade permite às feministas elaborarem estratégias destinadas a subverter os códigos culturais. Assim, aspectos que eram desqualificados para a produção do conhecimento, do ponto de vista masculino, agora se tornam argumentos políticos para a afirmação dos valores femininos, que parecem não somente permitir a produção de um conhecimento situado, a partir de uma experiência corporificada e encarnada, mas também de uma autoafirmação positiva de si como sujeito (mulher), em contínuo processo de devir. E, nessa luta por emancipação, elas não apenas se referem às experiências individuais, mas falam de um conjunto de mulheres que fazem as mesmas experiências. Nesse sentido, Bach (2010) tem afirmado que as mulheres não somente devem conhecer suas próprias experiências, mas também as das outras mulheres em suas circunstâncias de 
A produção acadêmica de mulheres professoras no campo do saber teológico: sujeição...

vida, porque isso se configura como uma estratégia para explicar criticamente a ausência das mulheres dentro dos processos de construção do conhecimento (FURLIN, 2018) ${ }^{23}$.

Analisa-se, nos conteúdo das narrativas das docentes, que a reflexão teológica que elas produzem, por perspectivas feministas ou de gênero, tem se constituído o que Lauretis (1994) define como uma das tecnologias de gênero ${ }^{24}$, porque produz um efeito positivo para o conjunto das mulheres, no processo de uma afirmação positiva de si, como sujeito de saber e como uma ferramenta de ressignificação das subjetividades femininas.

Mesmo que um número significativo das docentes entrevistadas afırme ter assumido as abordagens analíticas dos estudos de gênero e os pressupostos teóricos do feminismo como mediação para a produção do saber teológico, muitas vezes, a produção de algumas delas tende a se afınar mais com a perspectiva da Teologia da libertação $0^{25}$. Desde essa abordagem, elas utilizam uma linguagem inclusiva e questões específicas da vida das mulheres. Trata-se de um conhecimento que não chega a "subverter" a lógica epistêmica e, ainda, mostra-se resistente a uma ideia de feminismo "mais radical". Essa posição acaba tendo maior aceitação dentro da ordem que rege o sistema de saber teológico, como se pode ler nas entrelinhas da narrativa que segue.

Eu publiquei um livro e 60 artigos, mais ou menos, sobre CEBs, sobre temas de leituras bíblicas, interpretação de textos bíblicos ou algo que sempre tem a ver com a Bíblia e a nossa realidade. [...] Eu não produzo sempre na perspectiva das mulheres, trabalho feminista propriamente dito. Eu pego textos bíblicos ou realidades mesmo que sejam realidades de mulheres e faço um estudo onde entram todos os aspectos. Então o aspecto da mulher vai ser um entre outros, mas em geral é o mais picante. Eu não separo da análise o ponto de vista do pobre, o ponto de vista das outras discriminações, de sofrimento e de dor, que não é só feminina, então. Eu sempre falo das mulheres, mas também integrada às outras diferenças. Agora, quando eu pego um artigo, especificamente sobre as mulheres, inclusive foi um trabalho de iniciação científica, então o foco foi a questão feminina na abordagem feminista. Eu acho que quando estou fazendo isso, estou fazendo um trabalho de informação e de formação das consciências. Eu acho isso um trabalho muito útil. (Miriam, 66 anos).

Outras docentes relataram que nem sempre utilizam as abordagens feministas, mas buscam escrever partindo de sua própria experiência religiosa e das experiências que as mulheres fazem em suas comunidades cristãs, o que possibilita colocar em cena outros aspectos e valores que, em geral, não foram abordados pela teologia tradicional. Entretanto, de maneira paradoxal, nota-se certo cuidado para não fugir do rigor epistemológico, produzido pela intelligentsia masculina e considerado válido para este campo de saber, mesmo que, além disso, elas busquem dialogar com os saberes mais narrativos ou literários, que tornam a "teologia mais próxima da vida" como, às vezes, elas se referem ao saber que produzem. Nesse sentido, a narrativa que segue contempla a fala de outras professoras.

\footnotetext{
23- Nesse artigo é possível encontrar outros detalhes sobre as abordagens que as docentes entrevistadas adotam em sua produção acadêmica. 24 - Para Lauretis (1994), os discursos, as representações e as práticas são tecnologias porque produzem e ressignificam as subjetividades de gênero.

25 - Praticamente quase todas, além de se definirem feministas, dizem se afinar com a linha da teologia da libertação.
} 
Procuro sempre escrever teologicamente, lógico. Procuro o rigor e o aparato crítico, mas procuro, também, algo estritamente ligado à experiência e à espiritualidade. Não o teológico seco né, mas um discurso teológico, perpassado pela experiência das mulheres. Eu procuro sempre ressaltar isso, além disso, procuro trazer algum texto de fora da teologia, algum texto literário, poético, que abra o leitor para a leitura. (Débora, 60 anos).

Os substratos das narrativas de Miriam e Débora permitem afırmar que as docentes, como um sujeito sempre em devir e ainda marginal no universo teológico, não produzem um saber totalmente novo, mas um saber alternativo, fundado sobre outras categorias e acoplado ao saber "erudito" ou hegemônico no campo, porém com poder de exercer outros efeitos sobre as subjetividades femininas. Nesse sentido, segundo a proposta genealógica de Foucault (1999), pode-se afirmar que são saberes antes não considerados, pautados em novas categorias, como a de experiência das mulheres, cuja categoria se torna uma ferramenta para a crítica ao saber "masculino" universalizante. Na teoria foucaultiana, a genealogia é uma estratégia que ativa saberes situados, por muito tempo desqualificados e não legitimados, contra uma estrutura teórica unitária que hierarquiza saberes em nome do "discurso verdadeiro" e como uma forma de eliminar a tirania dos discursos englobantes. Isto é, trata-se da insurreição de saberes menores produzidos desde perspectivas situadas, por um sujeito marginal, "mulher"; insurreição de um saber que não se constituiu contra os conteúdos, os métodos e os conceitos da teologia, mas contra os efeitos do poder que este saber gera sobre a vida das mulheres, como um "discurso verdadeiro"26.

Certamente, é contra esses efeitos universalizantes que as docentes ativam a importância da categoria de experiência ou as "dores da vida cotidiana" das mulheres, que lhes permite produzir, não mais um saber abstrato e universal, mas um saber entrelaçado com o cotidiano das mulheres e, portanto, um saber que nasce de uma experiência situada. Segundo Braidotti (2004), a experiência das mulheres na vida real é central para sustentar o projeto de positivar a diferença sexual, no sentido da contragenealogia, que Adrienne Rich (1986) expressa na ideia de "política de localização". A política de localização significa que o pensamento, o processo teórico não é abstrato, universal, objetivo, nem indiferente, mas está situado na contingência da própria experiência e, por isso, é um exercício necessariamente parcial. Em outras palavras, a própria visão intelectual não é uma atividade mental desencarnada, antes se encontra estreitamente vinculada ao lugar da própria enunciação, ou seja, do lugar de onde alguém está falando. Isso, evidentemente, coloca-se como uma crítica ao falso universalismo de um conhecimento abstrato produzido do ponto de vista masculino.

\section{À guisa de conclusão}

Este estudo evidenciou duas das práticas acadêmicas (orientação e publicação de saber produzido) exercidas por mulheres docentes inseridas em um campo de saber

26- Vale ressaltar que no Brasil a chamada teologia feminista ou teologia e gênero ganhou maior expressão a partir do fim da década de 1980, constituindo-se um pensamento crítico ao universalismo abstrato da teologia católica tradicional. Mais detalhes em Furlin (2014). 
A produção acadêmica de mulheres professoras no campo do saber teológico: sujeição...

historicamente masculino, cujas ações operam como contramemórias, no sentido de desconstruir a imagem desqualificada de "mulher" do sistema simbólico masculino, para produzir uma imagem feminina positiva, que possibilita a legitimidade do devir sujeito feminino de saber. Isto é, são práticas que produzem um deslocamento subjetivo, uma vez que ressignificam os conteúdos de gênero em relação ao feminino, potencializando o agenciamento de si, como um sujeito com igual dignidade e capacidade para ocupar espaços de produção intelectual no campo teológico.

Se, por um lado, as práticas acadêmicas das docentes produzem um efeito de contramemória a um modelo de feminino da ordem simbólica masculina, em que as mulheres eram desqualificadas para atividades intelectuais, por outro lado, essas práticas também evidenciam a intensidade do trabalho acadêmico assumido pelas docentes, o que representa certa submissão às dinâmicas desiguais de gênero e de poder, que estruturam as práticas institucionais, como uma condição de uma afırmação positiva de si. Nessas relações contraditórias de cumplicidade às dinâmicas de gênero e de poder, que se estabelecem no campo do saber teológico, também se produzem desconstruções de significados e possibilidades de representação de, como "mulher", marcando este lugar por uma identidade feminina que é positiva, ou no sentido de Braidotti (2004), tratase de uma contramemória de determinado modelo de subjetividade feminina produzida pelos discursos da ordem social masculina. Ou seja, elas buscam marcar o universo de saber teológico como um lugar da produção de si (individual e coletiva), de um sujeito feminino que tem direito a este lugar social por uma trajetória, em parte pela formação profissional que possuem e, em parte, por causa de uma ausência histórica, de modo que a sua presença se torne visível e reafırme os valores que vêm do universo feminino.

A agência que as mulheres exercem nos processos de produção teológica, mesmo que nem sempre reconhecida, interage com as dinâmicas de poder existentes e visa produzir novos valores, significados e a possibilidade de neutralizar os efeitos de um saber globalizante. Butler (2009a) já afırmava que a ressignificação da subjetividade ou o agenciamento de si ocorrem da descontinuidade entre o poder que constitui o sujeito e o poder de resistência que ele assume e, no caso das docentes, isso parece ocorrer "dentro" e "fora" da lógica de gênero, instituída pela ordem simbólica masculina. Dentro, quando elas se submetem às práticas desiguais da lógica hierárquica do campo e fora, quando, por meio de práticas situadas elas produzem novos significados para o feminino.

Nessa lógica, as docentes, desde dentro do universo de saber teológico, criam suas possibilidades afastando-se do modelo de subjetividade do sistema simbólico produzido pela moral católica tradicional. Isto é, por meio de suas práticas situadas elas desconstroem e desnaturalizam os significados da cultura patriarcal que elas mesmas haviam assimilado. É, nesse sentido, que evidenciamos os deslocamentos subjetivos ou uma produção ética de si, que se constitui pela experiência vivida, em contextos situados da história presente. Porém, é um processo nunca concluído, porque a luta contra os efeitos do poder é contínua. Trata-se de uma subjetividade nômade, no sentido de Braidotti (2004), que está sempre em devir e que se reafirma pela diferença sexual positivada.

Isso nos faz compreender que suas práticas expressam muito mais a possibilidade de subjetivação ética do que sujeição. Contudo, trata-se de uma produção tensa e paradoxal 
que parece necessitar de uma relativa sujeição às dinâmicas hierárquicas de gênero, que operam nesse lugar de saber, historicamente marcado pela ação do sujeito masculino. Trata-se de uma agência ética, porque as mulheres se colocam como um sujeito que é capaz de pensamento e de produção reflexiva, cujo agenciamento ético de si opera dentro e fora da lógica de gênero androcêntrica. Isto é, produz-se em um "outro lugar", fora do centro do poder institucional e normativo do sistema simbólico masculino, mas nas práticas situadas das mulheres e, ao mesmo tempo, dentro das microrrelações de poder que se exercem nesse lugar de saber.

Ao incorporarem na produção acadêmica as abordagens e conceitos dos estudos feministas e de gênero, para problematizar e ressignificar as representações e imagens simbólicas da teologia católica tradicional, as docentes acabam produzindo outros discursos teológicos que, no sentido de Lauretis (1994), podem ser nomeados como "tecnologia de gênero", porque não somente produzem novos sentidos para o sujeito feminino do conhecimento, mas também efeitos nas subjetividades de quem acessa a teologia que é produzida por elas.

Considerando uma história de discriminação sexista e de ausência feminina nos lugares da produção e do ensino da teologia, bem como os desafios que as docentes enfrentam no momento presente, pode-se dizer que as práticas de agenciamento que elas constroem, por menor que sejam, tornam-se importantes, porque estabelecem certa autonomia em relação a uma estrutura hierárquica e masculina. Isso nos leva a pensar que o "revolucionário" não se encontra apenas nos grandes processos de transformação social que se concretizam no tempo e no espaço, mas também na produção de novos significados ou nas pequenas mudanças que ocorrem nas microrrelações sociais, que são tecidas no cotidiano da vida, como um modo novo de viver, de se produzir e de se reconhecer sujeito.

\section{Referências}

BACH, Ana María. Las voces de la experiencia: el viraje de la filosofía feminista. Buenos Aires: Biblos, 2010.

BOURDIEU, Pierre. Razões práticas. Campinas: Papirus, 2003.

BRAIDOTTI, Rosi. Diferencia sexual, incardinamiento y devenir. Mora, Buenos Aires, n. 5, p. 08-19, 1999.

BRAIDOTTI, Rosi. Feminismo, diferencia sexual y subjetividad nómade. Barcelona: Gedisa, 2004.

BRASIL. Ministério da Educação. Conselho Nacional de Educação. Relatório do parecer CNE/CES 241/99. Brasília, DF: MEC, 1999. Disponível em: http://portal.mec.gov.br/cne/arquivos/pdf/1999/pces241_99.pdf. Acesso em: 31 maio 2008.

BUTLER, Judith. Cambio del sujeto: la política de la resignificación radical de Judith Butler. In: CASALE, Roland; CHIACHIO, Cecília (org.). Máscaras del deseo: una lectura del deseo en Judith Butler. 1. ed. Buenos Aires: Catálogos, 2009b. p. 65-111.

BUTLER, Judith. Corpos que pesam: sobre os limites discursivos do "sexo". In: LOURO, Guacira Lopes (org.). 0 corpo educado: pedagogias da sexualidade. 2. ed. Belo Horizonte: Autêntica, 2007. p. 151-172. 
A produção acadêmica de mulheres professoras no campo do saber teológico: sujeição...

BUTLER, Judith. Dar cuenta de si mesmo: violencia ética y responsabilidad. Buenos Aires: Mutaciones, 2009a.

BUTLER, Judith. Mecanismos psíquicos del poder: teorías sobre la sujeción. 2. ed. Madrid: Cátedra, 2010.

BUTLER, Judith. Problemas de gênero: feminismo e subversão da identidade. Rio de Janeiro: Civilização Brasileira, 2003.

FELSKI, Rita. The gender of modernity. London: Harvard University Press, 1995.

FOUCAULT, Michel. A hermenêutica do sujeito. São Paulo: Martins Fontes, 2004.

FOUCAULT, Michel. História da sexualidade: 0 cuidado de si. 9. ed. São Paulo: Graal, 2007

FOUCAULT, Michel. Microfísica do poder. 14. ed. Rio de Janeiro: Graal, 1999.

FURLIN, Neiva. Cruzando fronteiras de gênero: a docência feminina em campos profissionais "masculinos". Cadernos Pagu, Campinas, n. 48, e164816, 2016.

FURLIN, Neiva. Relações de gênero, subjetividades e docência feminina: um estudo a partir do universo do ensino superior em teologia católica. 2014. 386 p. Tese (Doutorado em Sociologia) - Universidade Federal do Paraná, Curitiba, 2014.

FURLIN, Neiva. Teologia e gênero: a docência feminina em instituições católicas. Revista Eclesiástica Brasileira, Petrópolis, n. 284, p. 880-910, out. 2011.

FURLIN, Neiva. Um "modo feminino" de produzir e ensinar teologia: a diferença como projeto político de subjetivação e agenciamento. Educação \& Sociedade, Campinas, v. 39, n. 143, p. 283-300, 2018.

GEBARA, Ivone. Compartir los panes y los peces: cristianismo, teología y teología feminista. Montevidéu: Doble Clic, 2008.

HARDING, Sandra. Ciencia y feminismo. Madrid: Morata, 1996.

LAURETIS, Teresa de. A tecnologia de gênero. In: HOLANDA, Eloísa Buarque de (org.). Tendências e impasses: o feminismo como crítica da cultura. Rio de Janeiro: Rocco, 1994. p. 206-242.

LAURETIS, Teresa de. Genealogías feministas: un itinerario personal. In: LAURETIS, Teresa de. Diferencias: etapas de un camino a través del feminismo. Madrid: Horas y Horas, 2000. p. 7-31.

LIBANIO, João B.; MURAD, Afonso. Introdução à teologia: perfil, enfoques, tarefas. 8. ed. São Paulo: Loyola, 2011.

LOMBARDI, Maria Rosa. Perseverança e resistência: a engenharia como profissão feminina. 278 f. 2005. Tese (Doutorado em Educação) - Universidade Estadual de Campinas, Campinas, 2005.

MANNHEIM, Karl. A sociologia do conhecimento. In: MANNHEIM, Karl. Ideologia e utopia: introdução à sociologia do conhecimento cultura. São Paulo: Globo, 1976. p. 245-289. 
MINAYO, Maria Cecília de Souza de. Hermenêutica-dialética como caminho do pensamento social. In: MINAYO, Maria Cecília de Souza de; DESLANDES, Suely Ferreira (org.). Caminhos do pensamento epistemologia e método. Rio de Janeiro: Fiocruz, 2003. p. 83-107.

RICH, Adrienne. Nacemos de mujer: la maternidad como experiencia e institución. Valência: Cátedra, 1986. SCHIENBINGER, Londa. 0 feminismo mudou a ciência? Bauru: Edusc, 2001.

SCOTT, Joan W. Gênero: uma categoria útil de análise histórica. Educação \& Realidade, Porto Alegre, v.16, n. 2, p. 5-22, jul./dez. 1990.

SPIVAK, Gayatri C. Interview with Angela McRobbie. Block, New York, v.10, p. 5-9, 1985.

Recebido em: 24.04.2019

Revisado em: 01.10.2019

Aprovado em: 12.11.2019

Neiva Furlin é doutora em sociologia pela Universidade Federal do Paraná (2014), com estágio no Centro de Investigações Interdisciplinares em Ciências e Humanidades, da Universidade Nacional Autónoma de México (2012). Pós-doutora pela Universidade Estadual de Maringá (2018). Atualmente é professora e pesquisadora no Programa de Pós-Graduação em Educação, da Universidade do Oeste de Santa Catarina, Brasil. 